\title{
Analysis of Design For Assembly (Dfa) in Exhaust Product Design
}

\section{Analisa Design For Assembly (Dfa) Pada Perancangan Produk Knalpot}

\author{
Hamzah Achmad Putra ${ }^{1}$, Ribangun Bamban Jakaria ${ }^{2}$ \\ $\left\{\right.$ achmadputrahamzah@gmail.com ${ }^{1}$, ribangunbz@umsida.ac.id $\left.{ }^{2}\right\}$
}

Prodi Teknik Industri Fakultas Sains dan Teknologi Universitas Muhammadiyah Sidoarjo, Indonesia ${ }^{1,2}$

\begin{abstract}
Abstract. GRIP Exhaust is a small and medium industry which is engaged in manufacturing which produces mufflers. The production system in this company is to apply a production system made to order, where consumers can order exhaust products according to their requests. Designing exhausts according to technical specifications by applying the Design For Assembly (DFA) method and calculating the time required to assemble custom exhaust products into technical specifications by producing products according to user needs. With Design For Assembly (DFA) to make it easier and push time, but still focus on the function of the product itself and pay attention to the safety factor of its performance. custom stainless steel exhaust takes 2 hours to complete, rust-resistant quality, an efficiency value of 1.23, and has higher advantages and attractiveness in the eyes of consumers.
\end{abstract}

Keywords - Product Design; Design For Assembly (DFA); Handling and Insertion Code.

Abstrak. GRIP Knalpot merupakan sebuah industri kecil menengah yang bergerak dalam bidang manufacturing yang memproduksi knalpot. Sistem produksi yang terdapat di perusahaan ini adalah dengan menerapkan sistem produksi make to order, yang mana konsumen dapat memesan produk knalpot sesuai dengan permintaannya. Merancang knalpot sesuai spesifikasi teknik dengan menerapkan metode Desain For Assembly (DFA) dan menghitung waktu yang dibutuhkan untuk mengassembling produk knalpot custom menjadi spesifikasi teknik dengan menghasilkan produk yang sesuai dengan kebutuhan pengguna. Dengan Design For Assembly (DFA) untuk mempermudah dan menekan waktu perakitan, tetapi tetap fokus pada fungsi produk itu sendiri dan memperhatikan faktor keselamatan kinerjanya. knalpot custom material stainless steel membutuhkan waktu perakitannya yaitu selama 2 jam, kualitas tahan karat, nilai efisiensi 1,23, serta memiliki keunggulan dan daya tarik yang lebih tinggi di mata konsmen.

Kata Kunci - Perancangan Produk; Design For Assembly (DFA); Kode Handling and Insertion.

\section{Pendahuluan}

Knalpot merupakan bagian penting dari sebuah kendaraan bermotor. Karena itu di bidang otomotif produk ini mengalami perkembangan yang cukup pesat dan mempunyai daya tarik yang cukup besar dari pelanggan. Kualitas knalpot yang bagus dengan harga yang relatif murah dan terjangkau dapat menjadikan produk knalpot begitu diminati oleh banyak orang terutama knalpot custom. Knalpot custom tidak semata berfungsi sebagai aksesoris untuk mempercantik atau menambah gagah motor namun juga sebagai penambah tenaga motor. Salah satu IKM yang bergerak dalam bidang produksi knalpot custom adalah IKM Grip Knalpot.

Adapun permasalahan yang terdapat pada produk knalpot custom yang diproduksi oleh IKM GRIP yang dilihat dari segi kondisi knalpot custom yang kurang tahan lama, tenaga yang dihasilkan kurang serta nilai keindahan pada knalpot itu sendiri yang dirasa kurang baik. Dari permasalahan yang ada tersebut timbul ide untuk memangkas kekurangan produk knalpot custom sehingga mendapatkan nilai jual yang bersaing dengan kualitas produk knalpot custom yang baik.

Dengan melihat kekurangan yang ada maka digunakan metode Design For Assembly (DFA) yang berfungsi untuk merancang suatu proses perakitan produk yang membeberkan desain komponen maupum produk secara lebih detail yang dimulai dari awal hingga akhir proses produksi, sehingga dapat mengetahui akar permasalahannya dan dapat melakukan analisa perbaikan sebelum proses produksi dilakukan selain itu untuk menghitung waktu yang dibutuhkan untuk mengassembling produk knalpot custom agar menghasilkan produk yang sesuai dengan kebutuhan pengguna.

\section{A. Knalpot}

\section{TINJAUAN PUSTAKA}

[1] Knalpot merupakan alat peredam kebisingan yang dipasang pada kendaraan. Bagian knalpot terdapat bagian berbentuk tabung peredam suara yang biasa disebut silencer. Umumnya knalpot pada kendaraan berguna untuk 
meredam hasil ledakan di ruang bakar. Ledakan pembakaran campuran bahan bakar dan udara berlangsung begitu cepat diruang bakar. Ledakan ini menimbulkan suara yang sangat bising. Untuk meredam suara tersebut/gas sisa hasil pembakaran yang keluar dari katup buang tidak langsung dilepas ke udara terbuka. Gas buang disalurkan terlebih dahulu ke dalam peredam suara atau muffler di dalam knalpot. Inilah fungsi utama dari knalpot pada awalnya. Pada sepeda motor terjadi tekanan yang disebabkan oleh gas buang ketika keluar dari sistem pembuangan.

[2]Tekanan tersebut merupakan tekanan balik (back pressure). Beberapa mesin membutuhkan tekanan balik, sehingga ketika melepaskan sistem pembuangan menyebabkan kerusakan internal. Dengan telinga normal kita dengan mudah membedakan mana suara bising melebihi batas dan mana suara normal sebuah knalpot sepeda motor. Ada banyak bentuk tabung peredam knalpot dilapangan, tergantung dari kapasitas mesin kendaraan tersebut. Tinggi dan rendahnya tingkat kebisingan pada knalpot akan tergantung beberapa faktor antara lain volume knalpot, bentuk dan konstruksi knalpot, panjang saluran keluar antara mesin ke knalpot, dan juga bahan yang digunakan.

\section{B. Jenis Material}

[3]Jenis material yang digunakan pada pembuatan knalpot adalah material galvanis dan stainless steel. Galvanis adalah material seng (zink) yang melapisi besi, baja murni dan baja ringan untuk melindungi agar besi maupun baja tidak terjadi korosi. Tanpa lapisan pelindung seng, logam tetap terkena elemen dan berpotensi mengoksidasi dan menimbulkan korosi lebih cepat. Lapisan seng dapat mencegah air dan kelembaban serta elemen lain di udara dari korosi baja dibawahnya. Jika lapisan seng tergores atau terkena panas logam akan menjadi terbuka dan rentan terhadap korosi. Galvanis adalah logam putih kebiruan, logam ini mudah di tempa dan liat pada 110 - 150 derajat celsius dan menjadi sangat rapuh jika di panaskan di atas 200 derajat celsius. Jika di biarkan di udara terbuka yang lembab akan terbentuk lapisan garam-garam dasar tipis dan putih sebagai pelindung. Pada temperatur 419 derajad celsius galvanis dapat melebur dan titik didihnya 907 derajat celsius[4].

Stainless Steel (SS) adalah paduan besi dengan minimal 12\% kromium. Komposisi ini membentuk protective layer (lapisan pelindung anti korosi) yang merupakan hasil oksidasi terhadap krom yang terjadi secara spontan. Meskipun seluruh kategori SS didasarkan pada kandungan krom (Cr), namun unsur panduan lainnya ditambahkan untuk memperbaiki sifat-sifat SS sesuai aplikasinya. [5]Empat golongan utama SS adalah austenetic, ferritic, martensitic dan duplex. Keuntungan menggunakan stainless steel adalah tahan korosi yang tinggi yang memungkinkan untuk digunakan dalam lingkungan yang ketat, cerah dan mudah dipelihara permukaan sehingga menjadi pilihan yang mudah untuk diaplikasikan, memungkinkan untuk digunakan dengan ketebalan material yang berkurang selama nilai konvensional dan menghemat biaya, tahan terhadap dampak bahkan pada suhu ekstrim 650 815 derajat celcius, menghasilkan pilihan bahan paling murah jika dibandingkan dengan logam lainnya[6].

\section{Bahan dan Biaya}

Bahan (material) merupakan suatu komponen yang dapat digunakan oleh para pembuat produk atau pengrajin dalam merealisasikan produknya. Dalam merealisasikan produknya tersebut para pembuat produk akan merencanakan produk yang akan dihasilkan baik dari segi bahan baku, proses maupun output (hasil) dari produk jadi. Para pembuat produk juga akan memikirkan bagaimana produk yang dihasilkan akan dapat menarik minat konsumen dengan memiliki nilai jual yang tinggi dengan modal pembelian bahan yang sedikit dan dengan kualitas bahan yang bagus[7].

biaya adalah pengorbanan sumber ekonomis yang diukur dalam satuan uang yang telah terjadi atau kemungkinan akan terjadi untuk mencapai tujuan tertentu. Pengorbanan yang telah dikeluarkan diharapkan memiliki manfaat untuk sekarang dan akan datang. Biaya standar pada umumnya untuk membandingkan antara biaya yang dikeluarkan dengan biaya yang ditetapkan. Biaya standar merupakan hasil kajian teknik, gerak, dan waktu yang dilakukan dalam upaya menentukan jumlah bahan baku, tenaga kerja, dan jasa lainnya yang diperlukan untuk menghasilkan sebuah produk. Sehingga biaya standar ditentukan dimuka yang seharusnya dikeluarkan dalam proses produksi. Biaya (cost) adalah pengeluaran-pengeluaran atau nilai pengorbanan untuk memperoleh barang atau jasa yang berguna untuk masa yang akan datang, atau mempunyai manfaat melebihi satu periode akuntansi. Biaya ini diklasifikasikan dalam tiga unsur yaitu biaya bahan baku langsung, biaya tenaga kerja langsung dan biaya overhead pabrik

\section{Perancangan Produk}

[8]Perancangan atau pengembangan produk dibutuhkan oleh produsen dalam rangka mempertahankan atau meningkatkan pangsa pasar dengan cara mengidentifikasi kebutuhan-kebutuhan konsumen akan manfaat produk, kemudian mendesain produk tersebut, setelah itu sampai ke tingkat perencanaan pembuatan produk. Hal tersebut juga berkaitan dengan siklus hidup produk. Perancangan yang baik akan menghasilkan produk unggulan yang sesuai dengan keinginan atau kebutuhan customer. 
Tahapan siklus hidup produk (Product Life Cycle) terdiri dari perkenalan, perkembangan, kedewasaan dan penurunan. Dari siklus hidup produk tersebut terlihat bahwa perancangan produk sangat diperlukan untuk menjaga agar produk yang dihasilkan tersebut dapat laris dipasaran. Jika dilihat dari siklus hidup produk maka perancangan produk harus dilakukan pada saat produk berapa pada tahap kedua yakni pada tahap perkembangan dengan percepatan. Karena pada tahap kedua ini produk akan mengalami tingkat penjualan yang pesat dan produsen akan memperoleh keuntungan yang sangat besar pula[9].

\section{E. AutoCAD}

AutoCAD adalah sebuah program Computer Aided Design (CAD) yang digunakan untuk membuat gambargambar dua dimensi maupun model-model dalam bentuk dua atau tiga dimensi dan berwarna. AutoCAD dilengkapi dengan berbagai perlengkapan untuk membuat gambar-gambar dan pandangan-pandangan dengan kecepatan tinggi. Gambar yang dibangun oleh komputer dapat dilakukan atau digambar dan diplot dengan ketelitian sampai 13 desimal yang digunakan. Perekaman numerik dimensi yang kritis dan toleransinya lebih handal dibandingkan metode tradisional pembuatan skala secara manual. Kemampuan operator CAD untuk menyalin (copy), membuat array dan mengedit (menyunting) pekerjaan pada layar komputer dapat mempercepat proses menggambar. Jika operator dapat menyeragamkan sistemnya bagi suatu tugas khusus, maka kecepatan dalam bekerja dapat ditingkatkan menjadi lebih besar[10].

Kemampuan plotter (alat untuk memplot) yang dapat menghasilkan gambar yang tepat dan mudah dibaca merupakan keuntungan yang jelas yang melebihi metode kerja tradisional dengan menggunakan tangan. Keseragaman gambar CAD, yang menghasilkan gambar dengan ketebalan seragam, huruf dengan kualitas cetak, tanpa noda atau tanda-tanda pengeditan lainnya, dan hal ini sangat disukai oleh konsumen.

\section{F. Design For Assembly (DFA)}

Design For Assembly (DFA) adalah proses pengembangan dari desain produk yang digunakan untuk mempermudah dan menekan waktu perakitan, tetapi tetap fokus pada fungsi produk itu sendiri dan memperhatikan faktor keselamatan kinerjanya. Metode Design For Assembly bertujuan untuk mempermudah proses perakitan sehingga waktu yang dihasilkan dalam proses tersebut menjadi lebih efisien. Dengan terbagi dua faktor utama yang mempengaruhi waktu perakitan yaitu jumlah komponen produk dan kemudahan handling, insertion, dan fastening dari masing-masing part[9]. [11]Adapun langkah-langkah pengerjaan Design For Assembly (DFA) menurut Boothroyd G. (1994) adalah sebagai berikut:

- Tahap identifikasi produk, pada tahap ini rancangan produk awal diidentifikasi dengan menggunakan histogram untuk mencari penyebab yang paling dominan sehingga dapat memprioritaskan penyelesaian masalah.

- Tahap pemilihan komponen assembly, pada tahap ini masalah yang telah teridentifikasi kemudian di pilih berdasarkan komponen assembly (perakitan) rancangan produk awal menggunakan bill of material (BOM). BOM adalah daftar jumlah komponen, campuran bahan, dan bahan baku yang diperlukan untuk membuat suatu produk.

- Tahap membangkitkan alternatif atas fungsi, pada tahap ini mencari alternatif rancangan produk yang baru dengan cara mengeliminasi komponen yang tidak fungsional pada rancangan awal sehingga dapat mengurangi jumlah komponen yang digunakan ketika perakitan.

- Tahap mengevaluasi elemen komponen dalam fungsi. pada tahap ini mengevaluasi efisiensi rancangan awal dengan rancangan baru menggunakan metode Design For Assembly (DFA), dan parameter biaya proses spesifik, yang pada akhirnya merupakan perkiraan biaya manufaktur dengan dasar informasi atas komponen. Rumus efisiensi pada metode Design For Assembly (DFA) sebagai berikut:

$E=\frac{3 \times N M}{T M}$

keterangan:

$N M=$ Total banyaknya komponen yang dibutuhkan secara teoritis

$T M=$ Total waktu operasi handling dan insertion

Menghitung efisiensi $(E)$ tersebut dapat dilakukan dengan menemukan kode dan waktu kemudian dimasukkan dalam suatu tabel analisis DFA.

Tabel 1. Analisa DFA

\begin{tabular}{|c|c|c|c|c|c|c|c|c|c|}
\hline 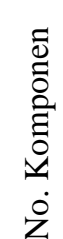 & 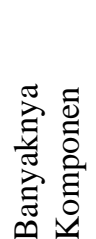 & 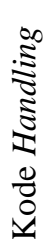 & 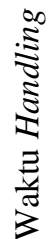 & 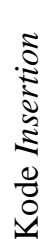 & 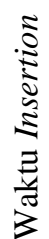 & 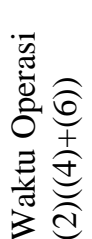 & 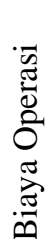 & 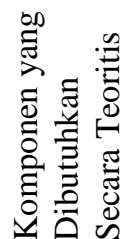 & 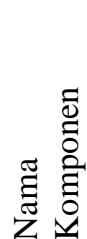 \\
\hline
\end{tabular}


Procedia of Engineering and Life Science Vol.1 No. 2 Juni 2021

Seminar Nasional \& Call for Paper Fakultas Sains dan Teknologi (SENASAINS 2 ${ }^{\text {nd }}$ )

Universitas Muhammadiyah Sidoarjo

\begin{tabular}{|c|c|c|c|c|c|c|c|c|c|}
\hline 1 & 2 & 3 & 4 & 5 & 6 & 7 & 8 & 9 & 10 \\
\hline 1 & & & & & & & & & \\
\hline 2 & & & & & & & & & \\
\hline 3 & & & & & & & & & \\
\hline$\ldots$ & & & & & & & & & \\
\hline $\mathrm{N}$ & & & & & & & & & \\
\hline & & & & & & TM & $\mathrm{CM}$ & NM & $\mathrm{E}=\frac{3 \times N M}{T M}$ \\
\hline
\end{tabular}

- Tahap stimulasi atas waktu penyelesaian, pada tahap ini hasil rancangan baru dianalisis berdasarkan waktu penyelesaiannya. Mengetahui dampak dari eliminasi komponen pada rancangan awal, kemudian waktu penyelesaian pada rancangan baru dan rancangan awal dibandingkan.

- Tahap analisis biaya yang dikeluarkan, pada tahap analisis biaya dilakukan untuk mengetahui apakah dengan adanya analisis DFA akan menjadikan biaya pembuatan produk berkurang atau tidak. Didalam analisis biaya yang diperhatikan yaitu biaya produksi anatara lain berupa biaya bahan baku dan pengadaan komponen yang digunakan.

- Tahap pemilihan alternatif, pada tahap ini alternatif rancangan dipilih dengan memperhatikan tingkat efisiensi pada perancangan produk baik dari waktu penyelesaian, biaya produksi, serta fungsional produk.

\section{METODE PENELITIAN}

Pada metode penelitian ini menjelaskan tentang kegiatan selama proses penelitian yang dimulai dari studi pustaka, studi lapangan, pengumpulan data, analisa data sampai dengan akhir proses penelitian.

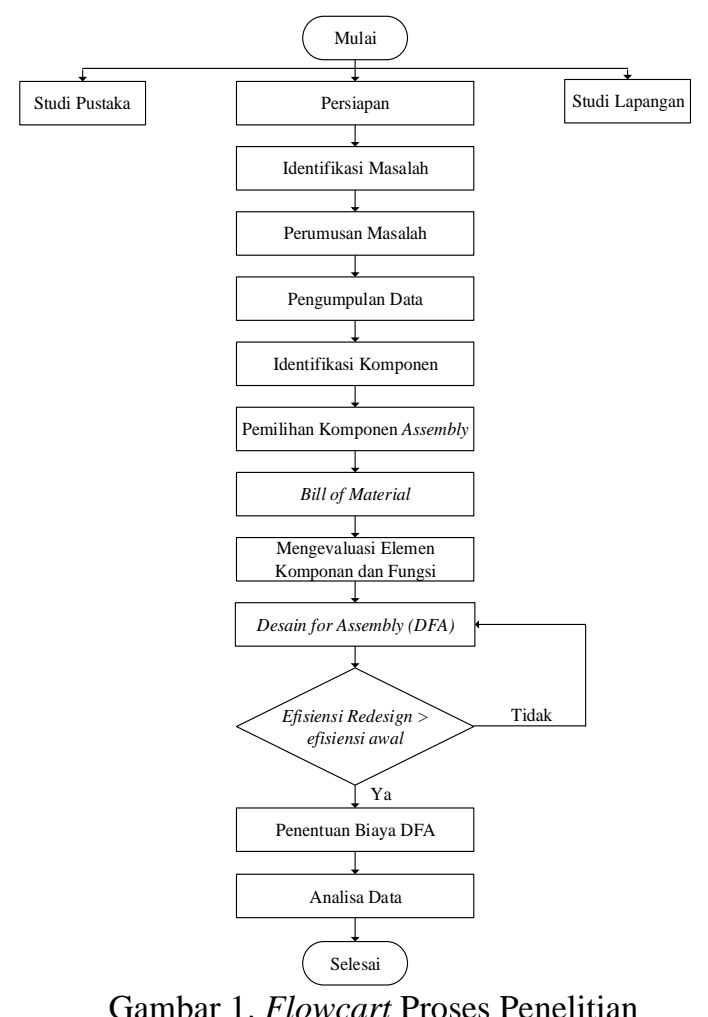

IV. HASIL DAN PEMBAHASAN

\section{A. Bill Of Material}

Adapun bill of material dari knalpot dapat dilihat pada gambar 2. 
Procedia of Engineering and Life Science Vol.1 No. 2 Juni 2021

Seminar Nasional \& Call for Paper Fakultas Sains dan Teknologi (SENASAINS 2 ${ }^{\text {nd }}$ )

Universitas Muhammadiyah Sidoarjo

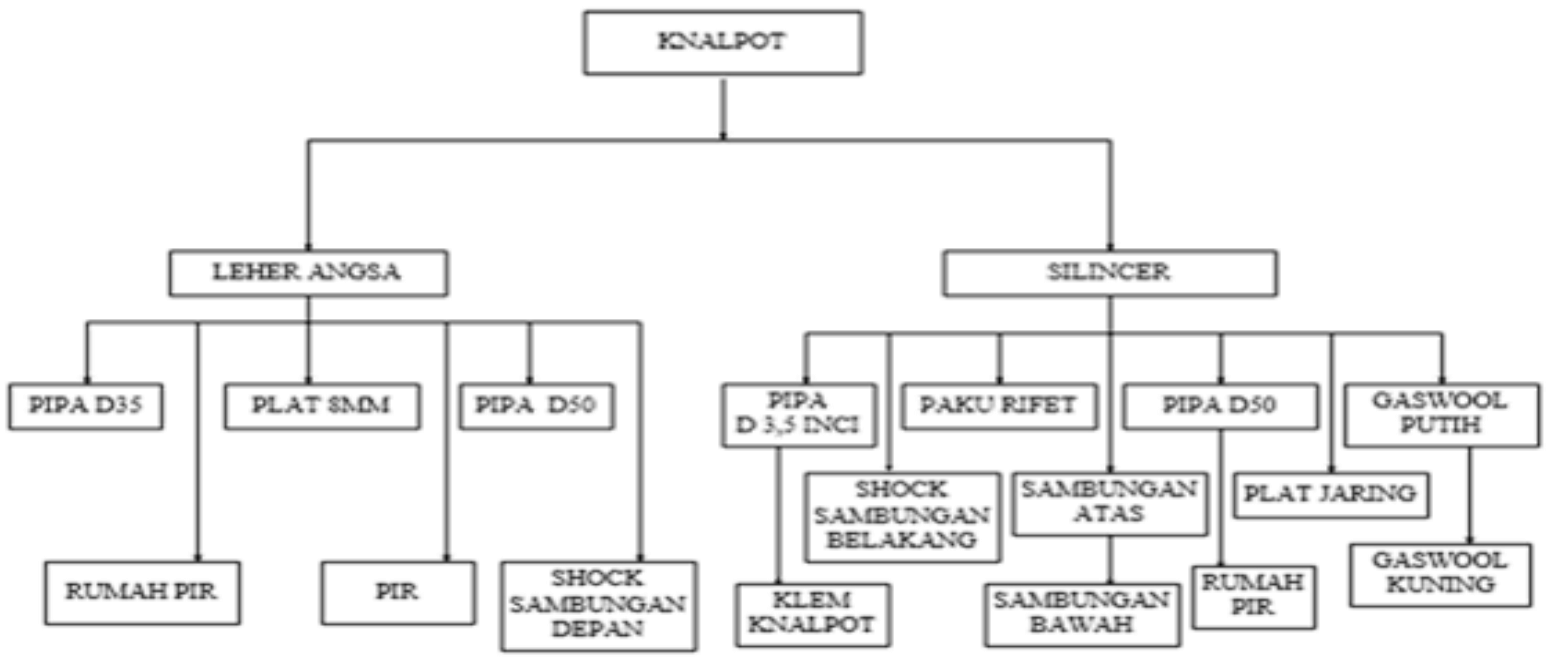

Gambar 2. Bill Of Material Knalpot

\section{B. Analisa Design For Assembly (DFA)}

Pada tahap analisa Design For Assembly (DFA) terdapat penentuan kode dan waktu yang di bagi menjadi dua yakni handling dan insertion yang mengacu pada tabel Boothroyd Dewhurst.

Tabel 2. Analisa DFA Knalpot Galvanis

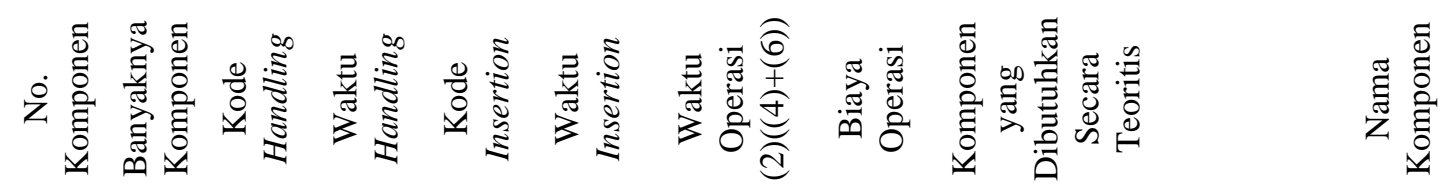

\begin{tabular}{cccccccccl}
\hline 1 & 2 & 3 & 4 & 5 & 6 & 7 & 8 & 9 & 10 \\
\hline 1 & 12 & 88 & 6,35 & 09 & 7,5 & 166,2 & - & $74,5 \mathrm{~cm}$ & Pipa $\phi 35$ \\
\hline 2 & 10 & 88 & 6,35 & 09 & 7,5 & 138,2 & - & $44 \mathrm{~cm}$ & Pipa $\phi 50$ \\
\hline 3 & 1 & 81 & 4,5 & 01 & 2,5 & 7 & - & $1 \mathrm{pcs}$ & Plat 8 mm (plendes) \\
\hline 4 & 4 & 82 & 5,1 & 06 & 5,5 & 42,8 & - & 4 pcs & Rumah pir \\
\hline 5 & 2 & 83 & 5,6 & 07 & 6,5 & 24,5 & - & 2 pcs & Pir \\
\hline 6 & 1 & 88 & 6,35 & 08 & 6,5 & 12,85 & - & 1 pcs & Shock sambungan depan \\
\hline 7 & 1 & 89 & 7 & 09 & 7,5 & 14,5 & - & 1 lembar & Plat 35 x 27cm \\
\hline 8 & 1 & 83 & 5,6 & 17 & 9 & 14,6 & - & 1 lembar & Gaswool putih \\
\hline 9 & 1 & 83 & 5,6 & 17 & 9 & 14,6 & - & 1 lembar & Gaswool kuning \\
\hline 10 & 10 & 87 & 5,85 & 18 & 9 & 148,5 & - & 10 pcs & Paku rivet \\
\hline 11 & 1 & 88 & 6,35 & 18 & 9 & 15,35 & - & 1 lembar & Plat jaring 35 x 15cm \\
\hline 12 & 1 & 88 & 6,35 & 29 & 11 & 17,35 & - & 1 pcs & Tutup atas \\
\hline 13 & 1 & 88 & 6,35 & 29 & 11,5 & 17,85 & - & 1 pcs & Tutup bawah \\
\hline 14 & 2 & 88 & 6,35 & 09 & 7,5 & 13,85 & - & $10 \mathrm{~cm}$ & Pipa $\phi 50$ \\
\hline 15 & 1 & 88 & 6,35 & 07 & 6,5 & 12,85 & - & $1 \mathrm{pcs}$ & Shock sambungan belakang \\
\hline 16 & 1 & 89 & 7 & 06 & 5,5 & 12,5 & - & 1 pcs & Klem knalpot \\
\hline & & Jumlah & & & 673,15 & CM & NM & E = $\frac{3 \times N M}{T M}$ \\
\hline
\end{tabular}

Tabel 3. Analisa DFA Knalpot Stainless Steel

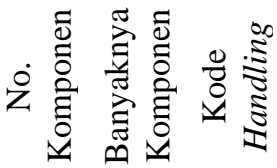

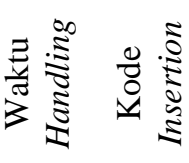

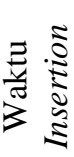

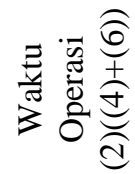
i⿱乛龰⿱艹

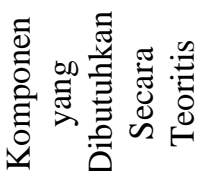

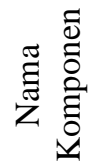


Procedia of Engineering and Life Science Vol.1 No. 2 Juni 2021

Seminar Nasional \& Call for Paper Fakultas Sains dan Teknologi (SENASAINS $2^{\text {nd }}$ )

Universitas Muhammadiyah Sidoarjo

\begin{tabular}{|c|c|c|c|c|c|c|c|c|c|}
\hline 1 & 2 & 3 & 4 & 5 & 6 & 7 & 8 & 9 & 10 \\
\hline 1 & 12 & 83 & 5,6 & 03 & 3,5 & 109,2 & - & $74,5 \mathrm{~cm}$ & Pipa SS $\varphi 35$ \\
\hline 2 & 10 & 83 & 5,6 & 03 & 3,5 & 91 & - & $44 \mathrm{~cm}$ & Pipa SS $\varphi 50$ \\
\hline 3 & 1 & 81 & 4,5 & 01 & 2,5 & 7 & - & $1 \mathrm{pcs}$ & Plat SS $8 \mathrm{~mm}$ (plendes) \\
\hline 4 & 1 & 88 & 6,35 & 08 & 6,5 & 12,85 & - & $1 \mathrm{pcs}$ & Shock sambungan SS depan \\
\hline 5 & 1 & 83 & 7 & 03 & 3,5 & 14,5 & - & $35 \mathrm{~cm}$ & Pipa SS $\varphi$ 3,5" \\
\hline 6 & 1 & 83 & 5,6 & 17 & 9 & 14,6 & - & 1 lembar & Gaswool putih \\
\hline 7 & 5 & 87 & 5,85 & 18 & 9 & 73 & - & $5 \mathrm{pcs}$ & Paku rivet \\
\hline 8 & 1 & 88 & 6,35 & 18 & 9 & 15,35 & - & 1 lembar & Plat jaring $35 \times 15 \mathrm{~cm}$ \\
\hline 9 & 1 & 88 & 6,35 & 29 & 11 & 17,35 & - & $1 \mathrm{pcs}$ & Tutup atas SS \\
\hline 10 & 1 & 88 & 6,35 & 29 & 11,5 & 17,85 & - & $1 \mathrm{pcs}$ & Tutup bawah SS \\
\hline 11 & 2 & 83 & 5,6 & 03 & 3,5 & 18,2 & - & $10 \mathrm{~cm}$ & Pipa SS $\varphi 50$ \\
\hline 12 & 1 & 88 & 6,35 & 07 & 6,5 & 12,85 & - & $1 \mathrm{pcs}$ & $\begin{array}{ll}\text { Shock } & \text { sambungan } \\
\text { belakang } & \\
\end{array}$ \\
\hline 13 & 1 & 82 & 5,1 & 02 & 5,5 & 10,6 & - & $1 \mathrm{pcs}$ & Plat klem knalpot \\
\hline \multicolumn{6}{|c|}{ Jumlah } & 429,2 & CM & NM & $\mathrm{E}=\frac{3 \times N M}{T M}$ \\
\hline
\end{tabular}

Dari tabel 2 dan tabel 3 dapat dilihat efisiensi (E) untuk perancangan ulang knalpot galvanis menjadi stainless steel memiliki hasil yang lebih besar yaitu 1,23 dibandingkan desain awal pada knalpot galvanis yaitu sebesar 0,68. Hal ini menunjukkan bahwa tingkat efisiensi penggunaan komponen yang lebih baik.

\section{Design Knalpot dengan Autocad}

Adapun gambar dari detail ukuran design konstruksi knalpot design konstruksi knalpot secara 3D yang dilihat dari berbagai sisi dengan menggunakan software autocad. Penggunaan software autocad ini bertujuan untuk mengetahui design konstruksi knalpot secara 2D maupun 3D pada knalpot dengan detail yang sesuai pada objek nyata. Berikut adalah gambar design knalpot dengan menggunakan software Autocad.

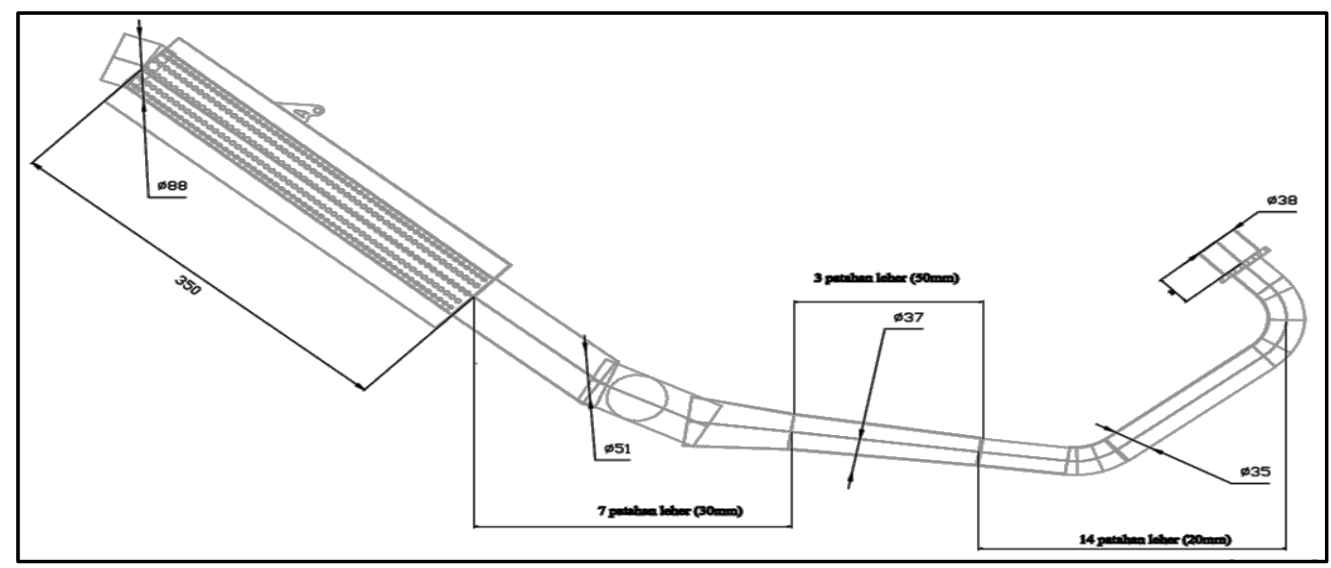

Gambar 1. Design Detail Ukuan

Pada gambar 4.4 terlihat konstruksi dari bagian sisi sebelah kanan dengan proyeksi 2 dimensi, dan setiap bagian pada knalpot tersebut memiliki ukuran. Pada leher angsa depan dengan pipa diameter 35, leher angsa pada bagian belakang pipa diameter 50, dan di lanjutkan dengan bagian silincer dengan diameter 3,5 inchi. 


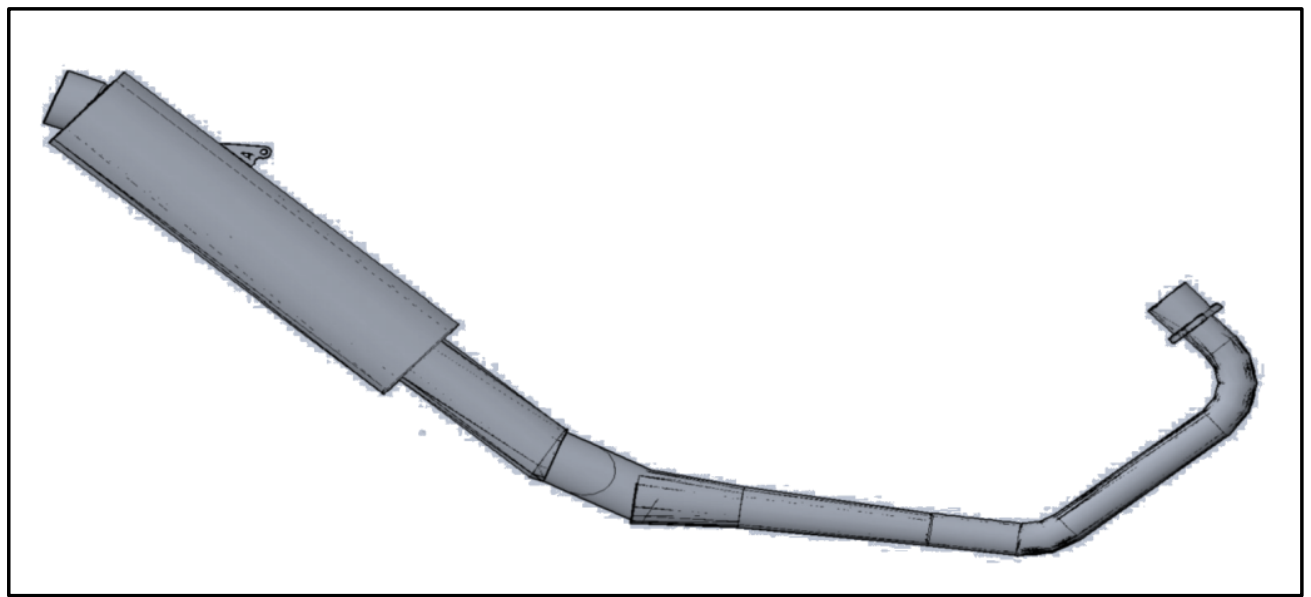

Gambar 2. Design Tampak Kanan 3D

Pada gambar 2 terlihat seluruh bagian knalpot dari tampak kanan dengan proyeksi 3 dimensi. Konstruksi terlihat lebih jelas dan padat dengan pemilihan material dan juga menyesuaikan dimensi yang pas dengan motor. Dengan bagitu motor akan terlihat pas sesuai dengan porsi

\section{Perbandingan Knalpot Galvanis dengan Knalpot Stainless steel}

Adapun data material galvanis dan material stainless steel diperoleh dari hasil pengamatan pada proses pembuatan knalpot yang diproduksi di IKM Grip.

Tabel 4. Perbandingan Material Galvanis dan Material Stainless Steel

\begin{tabular}{ccc}
\hline Kondisi & Material Galvanis & Material Stainless Steel \\
\hline Waktu Pembuatan & $5-6$ jam & 2-3 jam \\
\hline Biaya & $350.000-450.000$ & 800.000 \\
\hline Las & Las Karbit atau Las Asitilin & Las Khusus ( Las Argon) \\
\hline Berat & $1-2 \mathrm{~kg}$ & $3-5 \mathrm{~kg}$ \\
\hline Kualitas & Mudah berkarat & Tahan karat \\
\hline Efisiensi & 0.68 & 1.23
\end{tabular}

Dari Tabel 4. dapat dilihat bahwa material stainless steel lebih baik jika dibandingkan dengan material galvanis. Dari segi biaya material stainless steel memang memiliki harga yang relatif mahal jika dibandingkan dengan material galvanis. Namun jika dibandingkan dengan kualitas, daya tahan dan efisiensi maka material stainless steel memiliki keunggulan dan daya tarik yang lebih tinggi di mata konsumen.

\section{KESIMPULAN}

Kesimpulan yang terdapat pada penelitian ini adalah sebagai berikut, yakni cara melakukan rancang ulang knalpot dengan metode Design For Assembly (DFA) terdiri dari beberapa tahap yaitu mengidentifikasi produk knalpot yang akan dilakukan perancangan ulang. Dalam hal ini material knalpot yang digunakan adalah material galvanis dan stainless steel. Selanjutnya membuat Bill Of Material (BOM) yang digunakan untuk mengetahui jumlah komponen, dan bahan baku yang digunakan untuk kebutuhan produksi. Setelah itu mengetahui fungsi dari tiap-tiap material yang digunakan. Selanjutnya adalah menghitung efisiensi knalpot material galvanis dengan material stainless steel. Dari perhitungan efisiensi tersebut maka diketahui nilai efisiensi yang minimum dan dapat diketahui material knalpot mana yang perancangannya lebih efektif dan efisien yang dilihat dari segi waktu perakitan, biaya produksi, daya tahan produk, waktu pembuatan, kualitas bahan serta fungsi produk. Dan dari analisa perhitungan waktu assembly yang telah dilakukan dapat dilihat bahwa knalpot custom material stainless steel membutuhkan waktu perakitannya yaitu selama 2 jam. Dengan ketahanan material stainless steel memiliki daya tahan yang lebih lama, kualitas bahan material stainless steel tahan karat, nilai efisiensi yang dihasilkan material stainless steel mendapatkan angka 1,28, serta biaya material stainless steel memang memiliki harga yang relatif mahal dengan kualitas, daya tahan dan efisiensi maka material stainless steel memiliki keunggulan dan daya tarik yang lebih tinggi di mata konsumen. 


\section{UCAPAN TERIMAKASIH}

Saya mengucapkan terima kasih pertama-tama kepada Allah SWT, kepada keluarga saya, orang tua saya, dosen pembimbing dan teman-teman yang sudah membantu, memberikan motivasi serta dukungan dalam mengerjakan skripsi ini.

\section{REFERENSI}

[1] B. P. Pambudi, Lutfitona Ridho, "Knockoff Brand Sebagai Strategi Pemasaran Knalpot 'Palsu' Purbalingga," J. Ris. Ekon. Manajemen, Bisnis dan Akunt., pp. 1-8, 2018.

[2] Syarifudin, "Pengaruh Penggunaan Knalpot Standart Dengan Racing Terhadap Konsumsi Bahan Bakar Sepeda Motor Mio Gt Soul,” J. Nozzle, vol. 5, no. 1, pp. 106-108, 2016.

[3] S. Pareza and R. Lapisa, "Build Design Of Electric Bike As Energy Efficient Transportation Rancang Bangun Sepeda Listrik Sebagai Transportasi Hemat Energi," pp. 65-72.

[4] B. H. Tambunan, I. Koto, and I. Lubis, "Usaha Mengurangi Kebisingan Knalpot Produksi IKM di Kota Medan," J. Din., vol. 2, no. 14, pp. 1-7, 2014.

[5] P. Merek, D. Dan, K. Produk, J. Manajemen, and F. Ekonomi, "Pengaruh Merek, Desain Dan Kualitas Produk Terhadap Keputusan Pembelian Iphone Studi Kasus Pada Mahasiswa Stie Eben Haezar Manado,” J. Berk. Ilm. Efisiensi, vol. 16, no. 4, pp. 367-375, 2016.

[6] N. S. Nana Umdiana and K. Suprihatin, "Pengembangan Bersaing," Pengemb. Ukm Melalui Desain Prod. Dan Kemamp. Bersaing, pp. 169-176, 2018.

[7] N. Nazaruddin and U. Riau, "PENGEMBANGAN MESIN BAKSO DENGAN METODE DFMA ( DESIGN FOR MANUFACTURING AND ASSEMBLY ) PENGEMBANGAN MESIN BAKSO DENGAN METODE DFMA ( DESIGN FOR."

[8] R. Ginting, Perancangan Produk. y: Graha Ilmu, 2010.

[9] R. M. Veranika, “APLIKASI DESIGN FOR ASSEMBLY ( DFA ) PADA PERANCANGAN PRODUK VACCINE CARRIER,” vol. 2, no. 2, pp. 165-172.

[10] J. E. Fuller, Menggunakan AUTOCAD. Jakarta: Erlangga, 1990.

[11] A. Irfan et al., "USULAN PERBAIKAN PERANCANGAN PRODUK SMART LIGHT MENGGUNAKAN METODE DESIGN FOR ASSEMBLY BOOTHROYD-DEWHURST,” no. 23. 